\title{
Research on Network Ideology Security Related Problems and Countermeasures in Colleges and Universities
}

\author{
Manping Weng ${ }^{1}$ Dongdong Weng ${ }^{2, *}$ \\ ${ }^{1}$ Liming Vocational University, Fujian, Quanzhou, China
${ }^{2}$ Xiamen Institute of Technology, Fujian, Xiamen, China
${ }^{*}$ Corresponding author. Email: weng28911985@163.com
}

ABSTRACT

Due to the emergence of the Internet and new media, the propaganda platform and environment of ideology have had a huge impact with the rapid spread, new content and wide range. This paper focuses on finding solutions to the problems from the ways of network ideology security, emphasize that network ideological security education should run through the education process, open up new horizons, and gradually adjust the establishment of ideological safety supervision system from offline to online transition.

Keywords: Colleges and universities, Network ideology, Safety construction.

\section{THEORIES OF NETWORK IDEOLOGICAL SECURITY}

With the rapid development of Internet technology and big data, their network ideologies are also different in different countries and regions. Internet ideology refers to countries that are interested in the Internet and the Internet field, and is considered the "fifth space." This space spans multiple areas of the world, and is classified as a spiritual ideological area due to its characteristics [1-2]. Compared with different fields, its characteristics are virtual, latent and open. Now, users can browse the Internet in virtual reality, download and upload information, and can also spread and receive events from various regions at home and abroad through video, text and other forms.

\section{PROBLEMS FACED BY IDEOLOGICAL AND POLITICAL CONSTRUCTION IN COLLEGES AND UNIVERSITIES}

\subsection{The Impact of the Global Environment}

Due to the acceleration brought by the globalization environment and the development of information technology, the convenience of the Internet makes people love it. College students are more receptive to new things, so they master much faster than others. At the same time, other countries have gradually infiltrated
Chinese ideology by relying on their economic, cultural and Internet technology advantages, causing Western universal values [3], neoliberalism, or other erroneous ideas to negatively affect young Chinese college students.

\subsection{Superficial Cognition of Ideology, Some College Students lack Strong Awareness of Network Ideology Security}

When college students are affected by bad ideas, they will spread quickly on campus. The network of colleges and universities is vulnerable to hacker attacks, which can easily affect the correct understanding of network ideology by college students. At the same time, many college students' acceptance of network information is fragmented and one-sided, which affects their understanding of mainstream ideology to a large extent, and leads to deviations between many of their concepts and reality [4].

\subsection{The Current Situation of Decentralization of Education, Some Colleges and Universities lack Attention to Network Ideology}

Teachers' words and deeds are the key to the success of education and also represent the positive energy of social progress. However, some colleges and universities have insufficient awareness of the 
supervision and management of students' Internet access in the new era, and there are also big problems in guiding students' ability to correctly control cyberspace.

\section{COUNTERMEASURES TO THE PROBLEMS OF IDEOLOGICAL AND POLITICAL CONSTRUCTION IN COLLEGES AND UNIVERSITIES.}

\subsection{Strengthen Ideological Construction and Strengthen Political Beliefs}

Colleges and universities strengthen the building of political beliefs and strengthen spiritual support. Therefore, the party organizations in various universities should use political beliefs to build up the spiritual beliefs of university students.

\subsection{Strengthen Cultural Self-confidence and Create a Good Campus Cultural Environment}

A solid cultural confidence is the foundation, which paves the way for ideological construction. In the era of new media with ubiquitous networks and various platforms, we must have network thinking and platform awareness, strengthen cultural self-confidence, strengthen the construction of ideology in colleges and universities [5-6], and actively mobilize the wisdom and strength of teachers and students. In addition, colleges and universities should always pay attention to the network platform, make full use of the various databases they have to observe the state of thought and public opinion on the campus, and take active adjustment countermeasures.

\subsection{Improve College Students' Cognitive Ability of Ideology}

Colleges and universities must firmly grasp the right to speak, make full use of every ideological and political theory class in the classroom teaching of communication culture, and insist on strengthening it in improvement, so as to stimulate the consciousness and initiative of college students to receive ideological and political education. Secondly, through a variety of ways to deeply understand and master the psychological and ideological conditions of modern college students, implement relevant ideological safety education in a targeted manner, actively explore the resonance of popular issues, and help college students to think about real life through conscious inspiration The ideological security issues in the article effectively guide students to recognize the advantages and disadvantages of certain social thoughts and ideologies, and in a natural way, help college students clarify ambiguity and understanding, prevent thinking from being misled by wrong concepts, and let college students come to the right The conclusion.

\section{THE BASIC THEORY OF NETWORK IDEOLOGICAL SECURITY.}

\subsection{Relevant Factors in the Construction of Basic Theory of Network Ideological Security}

\subsubsection{The Main Body of Network Ideological Security}

The subject refers to the main part of things, which determines the direction of changes and development of things. The main body of network ideology security is a certain group of natural persons who generate ideology by receiving, cognizing and communicating network information [7]. From the perspective of social development, the security of network ideology and the three main bodies are as follows. In order to consolidate state power and maintain social stability, the main body of network ideology operation refers to the use of state power to guide the development of network ideology in a direction conducive to national governance and social development. Second, the people living in the country and region and overseas Chinese participate in the political and economic life of their country or region. Learn about domestic and foreign information through the Internet, express your own views on national policies, social phenomena, and economic development, and publish or convey interest appeals that are closely related to yourself, forming the ideology of the network society, which is the main body of network ideological changes. Third, the role of opposing or hostile forces on the spiritual level of a country or regional power.

\subsubsection{Objects of Network Ideological Security}

An object is an object that exists objectively and can be perceived by the subject. It has a counteraction with the subject and thus affects the development and change of the subject. However, the security object of cyber ideology refers to the various measures and activities taken by the security subject of cyber ideology to achieve their own goals and have a positive or negative impact on the audience [8], especially the cognition and social identity of the people of the country. Sum. In other words, the various phenomena that exist in the 
cyber world are closely related to the object of cyber ideological security construction. At the same time, these network phenomena and events continue to affect the changes of network ideology, and they also constantly respond to the decisions and behaviors of the security subjects of the network ideology.

\subsubsection{The Characteristics of Network Ideological Security}

There are five characteristics of cyber ideological security as shown below. As follows: First, network security is integral, not broken and separated, and network security is very important, because network security awareness is a key factor in ensuring network security. The second one is dynamic. Internet ideology is safe because it is a dynamic process, not static, but constantly changing, advancing with the times with the development of society and economy. Third, network security is open, not just being yourself behind closed doors. The network environment is an open space, and everything related to the network has an open attribute, and the security of network ideology is no exception. Fourth, relativity. The security of cyber ideology exists relatively, and there is no absoluteness. There is no absolute network ideology security, that is, the degree of network ideology security is less than $100 \%$, and it can be considered safe only if the network ideology is in a relatively stable state. Fifth, cyber ideological security is generally not isolated. In other words, the security of network ideology needs to be jointly constructed by multiple fields in order to maintain a better ideological stability. And no matter which aspect can guarantee the accuracy and scientificity of network ideology security. Therefore, it is necessary to accelerate the construction of a secure operating system, fully grasp the security situation, and improve the comprehensive defense capabilities and counter-offensive capabilities of network security.

\subsection{Factors Affecting the Basic Theory of Network Ideological Security}

\subsubsection{Time Factors First of All, the Era of Economic Globalization}

In the mid-1980s, the embryonic form of economic globalization was formed. However, in this era of economic globalization, the continuous exchange and integration of global economy, trade, culture, and technology has brought many benefits to countries around the world. For example: the allocation of resources is more optimized and reasonable, the development model is constantly innovated, and the continuous progress of human civilization is promoted. Therefore, China also attaches great importance to the era of economic globalization and formulates development strategies to promote better development of itself. In addition, the Internet is a very convenient communication tool and information transmission medium. It breaks through the barriers of space, conducts barrier-free communication, greatly reduces time and transportation costs, and quickly stimulates the great development of economic globalization. Moreover, the field of social ideology is the content of the ideological, cultural and spiritual level, which fits the characteristics of the network platform system. Therefore, with the help of the Internet, the influence, competitiveness, and discourse power of the ideology of various countries are constantly expanding, and the competition and struggle between each other are gradually intensifying. Therefore, it is imperative to research and build network ideological security. . Secondly, with the advent of the "Internet + " era, the most notable thing is the vigorous development of information technology. After the emergence of the three major portals, Sina, Sohu, and Netease, Premier Li Keqiang of the State Council formally proposed the concept of "Internet $+"$. In this era, even the development of traditional industries depends on the upgrading of the Internet platform, and many emerging industries are constantly being born in the Internet environment. Therefore, there will be no development without the Internet, and it will be eliminated by the times without relying on the Internet. This has become the consensus of the Chinese society. In the changing process of the "Internet + " era, tremendous changes in industry, social life and ideology are inevitable. Comrade Xi Jinping grasped the characteristics of the development of the times, objectively analyzed the development situation of China and the world, and put forward a series of new viewpoints, new ideas and new conclusions on the security issue of cyber ideology. In summary, the security of network ideology has characteristics of the times.

\subsubsection{Realistic Elements}

After 30 years of rapid development, China is in a special historical critical period. The increasing diversification of social life and social consciousness has caused many changes in social thinking. However, due to the emergence of certain hostile forces, they use various banners of public opinion to confuse the public, 
so we must keep a clear head before we can firmly move forward. This is because before the Internet was widely used, ideology was mainly propaganda output based on traditional media, such as television, radio, various paper media and publicity boards, and so on. The spread of its ideology is very limited, and government departments can control the negative impact within a certain range, so it is difficult for the ideology to pose a substantial threat to family safety.

\subsubsection{Network Factors}

The network factors of network ideology security have the following three aspects: the virtuality of the network, the concealment of the network, and the development of the network. With the rapid development of the Internet, people have begun to face different living spaces and opened up a new way of life. Then, with the development of network technology, it formed a second living space, that is, network virtual space. In this space, simplification and virtuality make people's lives more convenient and better enjoy freedom and equality. Therefore, when virtual reality is regarded as a social existence, network ideology is gradually formed. The concealment of the Internet means that people can hide their true identities in cyberspace. Through the identities of "invisible people", they can exchange ideas in this virtual world, so that people can have real spiritual communication on the Internet without any worries. . However, the concealment of the network has two effects. On the one hand, in addition to ensuring that your privacy is protected and not affecting your actual life situation, you can talk and understand as needed, and it can also be used to vent your feelings and find solutions. But on the other hand, this kind of concealment will provide some illegal elements with opportunities to take advantage of it, which constitutes unethical or illegal behavior. The openness of the Internet, with the emergence of Internet technology, people have broken the traditional physical space barriers, surpassed the concept of reality identification and the concept of belonging groups, and can enjoy the freedom gained from the virtual world at low cost. In the virtual space, people can find the resources they want according to their own wishes, express their views, and spread their views on certain phenomena. This shows that there is strong tolerance in the development of the Internet.

\section{CONCLUSIONS}

Nowadays, with the high popularity of the Internet and the rapid development of the global economy, the Network has become an indispensable daily necessities for people, bringing many conveniences to people and making the network an emerging space for competition among countries. The Internet is not just about ordinary Internet users, but also about the future of the whole country. Therefore, doing this work well has very important practica significance and long-term significance. In network security, the issue of network ideology security is very important and cannot be ignored. To strengthen the construction of network ideology security in Chinese universities and prevent the infiltration and destruction of non-mainstream ideology at home and abroad is the key link to realize the great rejuvenation of the Chinese nation.

This paper based on the related theories, this paper analyzes the current network ideological security situation at home and abroad, combing the current network security context ideology in our country, summarizes the college network ideological security causes of problems, and puts forward the objective opinions and Suggestions, to sum up, our country university ideology construction still needs to be constantly improved, to improve the college students Power, cohesion and charisma, establish a correct network ideology, promote college students to distinguish right from wrong, firm forward road.

\section{ACKNOWLEDGMENTS}

(1) Liming Vocational University on Approving the Establishment of School-level General Projects in 2020 (Li Da [2020] No. 43) "University Network Ideological Security Related Issues and countermeasures research" (LAS202028)

(2) The thirteenth Five-year Plan of Fujian provincial Ministry of Education, Project of 2020. "Reach on the cultivation of "Craftsman Spirit" in undergraduate specialty teaching in colleges and universities" (FJJKCG20- 6)

(3) The 2020 Lifelong Education Research Project in Fujian Province "Research on the Construction of the Intelligent Elderly Care Service System in Fujian Community Based on the Concept of Lifelong Education-Taking Xiamen as an Example" (ZS20236)

(4) The 2020 academic research fund project of Xiamen Institute of Technology Business School 


\section{REFERENCES}

[1] Zhang Ce. Feng Congcong. Wang Mingfei, "Study on the Challenges and Countermeasures of Ideological Work in Colleges and Universities" [J]. Party History Bocai (Part 2), 2019(11): 67-68.

[2] Guo Yani. Analysis of the Dilemma and Path of University Ideology Construction [D]. Harbin Institute of Technology, 2018: 5.

[3] He Ruihu, "Thoughts on Effective Responses to Ideological and Political Education in Colleges and Universities from the Perspective of Preventing and Resolving Ideological Risks" [J]. Journal of Nanchang College of Education, 2019, 34(04): $1-4+36$.

[4] Wu Sponsor. Research on Current China's Cyber Ideological Security Issues [D]. Jilin University, 2017: 3 .

[5] Xu Doudou. Strengthen cultural self-confidence and strengthen ideology [N]. Xiamen Daily, 2018-02-26 (A09).

[6] Jia Yang "Give full play to the leading role of teachers in the construction of ideology in colleges and universities" [J]. Cultural and Educational Data, 2016(32): 80-81.

[7] Liu Shunhou "Basic Requirements for Political Construction of Party Organizations in Colleges and Universities in the New Era" [J]. Ideological and Theoretical Education, 2019(11): 77-81.

[8] Du Guangwei. Wu Wenjuan, "Tongtong", the true essence of cultural self-confidence, "doing real" ideological work" $[\mathrm{J}]$. Beijing Education (Moral Education), 2018(02): 47-50. 